\title{
Common Causes Associated With Occupational Injuries in Iranian Health Care Workers: A Systematic Review and Meta-Analysis Study
}

\author{
Zhila Fereidouni ${ }^{1}$, Azizallah Dehghan ${ }^{2}$, Majid Najafi Kalyani ${ }^{3^{*}}$ \\ ${ }^{1}$ School of Nursing, Fasa University of Medical Sciences, Fasa, Iran \\ ${ }^{2}$ Noncommunicable Diseases Research Center, Fasa University of Medical Sciences, Fasa, Iran \\ ${ }^{3}$ Department of Medical-Surgical Nursing, School of Nursing and Midwifery, Shiraz University of Medical Sciences, Shiraz, Iran
}

Corresponding Author: Majid Najafi Kalyani, PhD, Assistant Professor, Department of Medical-Surgical Nursing, School of Nursing and Midwifery, Shiraz University of Medical Sciences, Shiraz, Iran. Tel: +98-7136474254, Email: majidnajafi5@yahoo.com

Received April 28, 2018; Accepted June 8, 2018; Online Published June 25, 2018

\begin{abstract}
Introduction: Occupational injuries are the most important hazards threatening health care workers (HCWs) and cause contact with infectious agents and the transmission of diseases such as AIDS and hepatitis B and C. This study is a meta-analysis of studies on the common causes of occupational injuries in Iran.

Methods: In this meta-analysis, all articles on injuries to HCWs in Iran published on local and international databases during the period 2000-2016 were assessed for eligibility. Using the keywords occupational injury, needle stick injury, healthcare workers, and Iran, searches of local and international databases were conducted. From 60 articles screened, 19 were determined to be relevant and were subsequently analyzed.

Results: The results of this meta-analysis showed that needles and injections were the most common causes of occupational injuries in HCWs. The pooled prevalence of needle stick was estimated to be $52.95 \%$ (46.05\%-59.84\%) based on the reports of 19 studies with a total of 8703 participants. The pooled prevalence rate of injections was estimated to be $33.56 \%(27.43 \%-37.90 \%)$.

Conclusions: The results showed that routine activities of HCWs most commonly result in occupational injuries. Given the high prevalence of needles and injections as causes of occupational injuries in Iranian HCWs, more attention and the development of effective strategies to reduce these injuries are necessary.

Keywords: Occupational Injuries, Sharp Injuries, Health Care Providers, Iran

Citation: Fereidouni Z, Dehghan A, Najafi Kalyani M. Common causes associated with occupational injuries in Iranian health care workers: a systematic review and meta-analysis study. Int J Med Rev. 2018;5(2):77-81. doi:10.29252/JJMR-050206.
\end{abstract}

\begin{abstract}
Introduction
Occupational injuries are the most important hazards threatening health care workers (HCWs). Among occupational injuries, needle stick injuries (NSIs) are one of the most common injuries to HCWs during work. ${ }^{1}$ HCWs are vulnerable to contact with patients. ${ }^{2}$ NSIs in HCWs significantly increase the risk of transmission of infectious diseases such as AIDS and hepatitis B and C.3.-5 According to the World Health Organization (WHO), there have been 16000 cases of hepatitis C, 66000 cases of hepatitis B, and 1000 AIDS cases following occupational exposure. ${ }^{6}$ In addition to the transmission of infectious diseases, these injuries can endanger the mental health of HCWs and impose heavy costs resulting from the treatment of infected personnel. ${ }^{5,7}$ In addition to the risk of illness and death, psychological damage, and long-term disability, occupational exposure to sharp objects is also associated with fear, tension, and
\end{abstract}

anxiety. ${ }^{8,9}$ Furthermore, it imposes a heavy economic burden on countries..$^{10} \mathrm{~A}$ serious infection with blood-borne viruses can cost $\$ 1$ million because of tests, follow-up, disability, and loss of work; the cost of preventing occupational injuries is estimated to be $\$ 30000^{10,11}$ Despite the high prevalence of this occupational injuries among HCWs, they can be prevented..$^{12-14}$

Identifying the factors associated with occupational injuries helps health policy-makers minimize and prevent these types of injuries. There are no coherent reports on the common causes of occupational injuries among Iran's HCWs; thus, this meta-analysis aimed to determine precisely the common causes of occupational injuries in Iranian HCWs.

\section{Methods}

This is a systematic review and meta-analysis of the research conducted on occupational injuries among HCWs in Iran.

Copyright (C) 2018 The Author(s). This is an open-access article distributed under the terms of the Creative Commons Attribution License (http:// creativecommons.org/licenses/by/4.0), which permits unrestricted use, distribution, and reproduction in any medium, provided the original work is properly cited. 
The Preferred Reporting Items for Systematic Reviews and Meta-Analyses (PRISMA) guidelines (Figure 1) were used to conduct and report the results of this study.

\section{Search Strategy and Eligibility Criteria}

The main questions of the researcher in this meta-analysis were, "What are the most common causes of occupational injuries in Iranian HCWs?" and "What is the prevalence rate of common causes of occupational injuries in Iranian HCWs?" To answer these questions, articles on occupational injuries in Iranian HCWs that had been published in local and international databases were searched using the key words "Occupational Injury", "Needle Stick Injury," "Risk Factors, Health Care Workers" and "Iran." The inclusion criteria for articles were the availability of the full text, focus on causes of occupational injuries and needle-stick injuries, publication in Persian or English, and publication occurring in the 16year study period. Articles in languages other than Persian or English, those lacking clarity of methods, and those lacking the proper reporting of results were excluded.

\section{Data Collection and Extraction}

Searches were performed for all articles published in the 16year period of 2000 to 2016 in Persian or English on local databases (SID, Mag Iran, Iran Medex, Iranian Medical Library) as well as international databases (Google Scholar, ISI Web of Knowledge, Scopus, PubMed, and Science Direct). Data extracted from the relevant studies included author(s) name, publication year, location of research, sample size, and prevalence of common causes (needle as the common object and injections as the common activity).

\section{Data Analysis}

The extracted data was analyzed using STATA 11 software. $I^{2}$ was used to evaluate the heterogeneity of the data. The random effects model was used because of the heterogeneity of the results of the selected studies.

\section{Results}

In the initial search, 60 articles were determined to be relevant and assessed for eligibility. Of those, 41 were excluded due to not being pertinent to the topic of the study and of low quality. Ultimately, 19 articles that were related to the research questions and met the criteria were selected and analyzed based on the PRISMA statement (Table 1)..$^{8,11,15-31}$

HCWs included nurses, doctors, midwives, operating room technicians, anesthetic technicians, dentists, and students in the fields of medicine, nursing, midwifery, dentistry, and emergency medicine. Most of the studies looked at a combination of HCWs.

A total of $8703 \mathrm{HCW}$ s and students were surveyed in the selected studies. The highest prevalence rates of needle as an associated factor of occupational injuries were reported by Nazmieh (79.9\%), Kouhestani (76.92\%), and Bijani (70.9\%), and the lowest prevalence rates were reported by Mirzaei (33.3\%), Gholami (35.71\%), and Aghadoost (37.5\%). The prevalence of NSI among Iranian HCWs with a sample size of 8703 was estimated to be $52.95 \%$ (95\% CI: - 46.05-59.84) using the random effect model (Figure 2). The funnel plot to assess publication bias for prevalence of needle as a common object in occupational injuries is presented in Figure 3.

The highest prevalence rates of injection as the cause of occupational injuries were reported by Parsapili (64.9\%), Rakhshani (54.6\%), and Vahedi (49.94\%), and the lowest prevalence rates were reported by Gholami (14.47\%), Ehsani (18.91\%), and Adib-Hajbagheri (22.2\%). The prevalence of injections among Iranian HCWs with a sample size of 8703 was estimated to be $33.56 \%$ (confidence interval 95\%-27.4337.90) using the random effect model (Figure 4). The funnel plot to assess publication bias for the prevalence of injections as a common activity in occupational injuries is presented in Figure 5.

\section{Discussion}

In this meta-analysis study, the analysis results suggested that needles and injections are the most common causes of occupational injuries in Iranian HCWs. The prevalence of NSIs among Iranian HCWs was estimated to be $52.95 \%$ (confidence interval 95\%-46.05-59.84) using the random effect model. These results indicate the high prevalence of

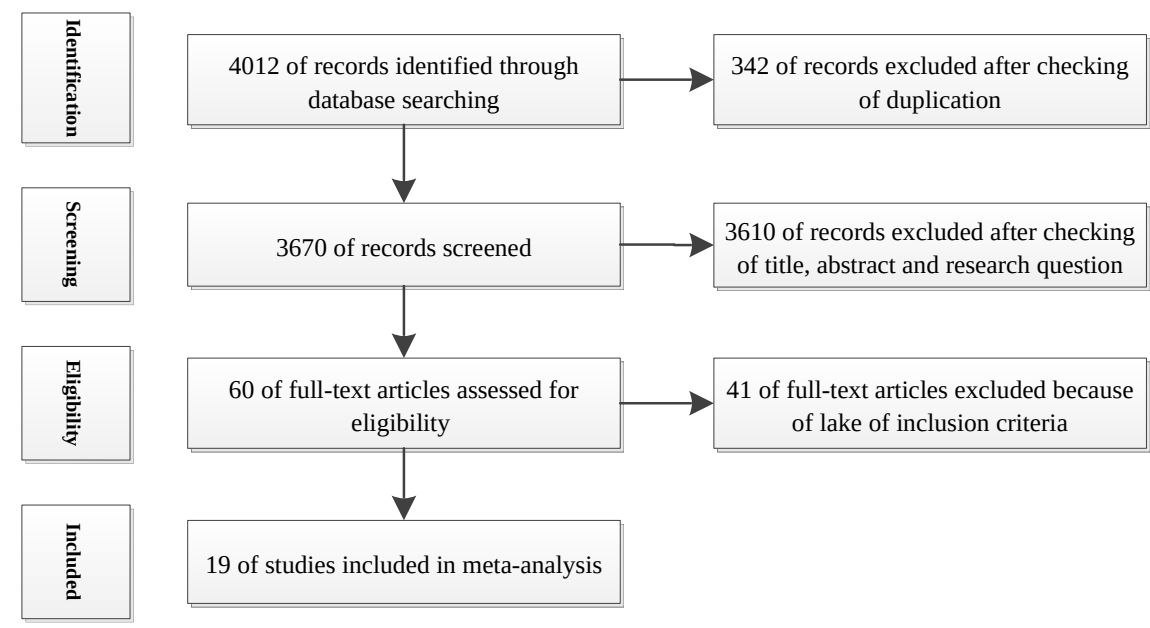

Figure 1. Flow Chart of the Study. 
Table 1. Characteristics of Reviewed Studies

\begin{tabular}{|c|c|c|c|c|c|c|}
\hline First Author & Year & City & Sample Size & Needle & Injections & Reference \\
\hline Adib-Hajbagheri M & 2013 & Kashan & 298 & $46.5 \%$ & $22.2 \%$ & 8 \\
\hline Mahmoudi N & 2015 & Tehran & 100 & $45.98 \%$ & $24.14 \%$ & 15 \\
\hline Gholami A & 2013 & Neyshabour & 384 & $35.71 \%$ & $14.47 \%$ & 16 \\
\hline Shoghli A & 2012 & Zanjan & 593 & $53.8 \%$ & $26.4 \%$ & 17 \\
\hline ParsaPili J & 2013 & Tehran & 515 & $49.6 \%$ & $64.9 \%$ & 18 \\
\hline Mirzaei M & 2011 & Hamedan & 120 & $33.3 \%$ & $44.0 \%$ & 19 \\
\hline Rezaei SH & 2013 & Tehran & 514 & $40.3 \%$ & $31.33 \%$ & 20 \\
\hline Rezaei SH & 2012 & Tehran & 991 & $55.08 \%$ & $24.7 \%$ & 11 \\
\hline Hashemi SH & 2012 & Hamedan & 700 & $60.7 \%$ & $29.0 \%$ & 21 \\
\hline Ehsani SR & 2012 & Tehran & 328 & $43.91 \%$ & $18.91 \%$ & 22 \\
\hline Kouhestani HR & 2010 & Arak & 52 & $76.92 \%$ & $40.38 \%$ & 23 \\
\hline Rakhshani F & 2009 & Zahedan & 231 & $55.4 \%$ & $54.6 \%$ & 25 \\
\hline Joneydi Jafari $\mathrm{N}$ & 2008 & Tehran & 613 & $70.6 \%$ & $24.4 \%$ & 26 \\
\hline Bijani B & 2012 & Qazvin & 172 & $70.9 \%$ & $36.4 \%$ & 27 \\
\hline Nazmieh H & 2005 & Yazd & 1020 & $79.9 \%$ & $47.6 \%$ & 28 \\
\hline Vahedi M S & 2006 & Kurdistan & 847 & $43.57 \%$ & $49.94 \%$ & 29 \\
\hline Aghadust D & 2007 & Kashan & 678 & $37.5 \%$ & $31.6 \%$ & 30 \\
\hline Afrasiabifar A & 2001 & Yasuj & 159 & $45.0 \%$ & $26.4 \%$ & 31 \\
\hline
\end{tabular}

the needle as the most common device causing injuries. In a study by Kebede et al in Ethiopia, the needle was reported as the most common device among HCWs (47.2\%), ${ }^{32}$ which is consistent with the current findings in Iran. As the needle is the most commonly used device in routine care by HCWs, the high prevalence of injuries caused by this device is reasonable. Martins et al showed that syringe needles were responsible for $45.8 \%$ of injuries. ${ }^{33}$ The slight difference between the current findings and those of Martins et al can be attributed to different organizational and environmental settings in

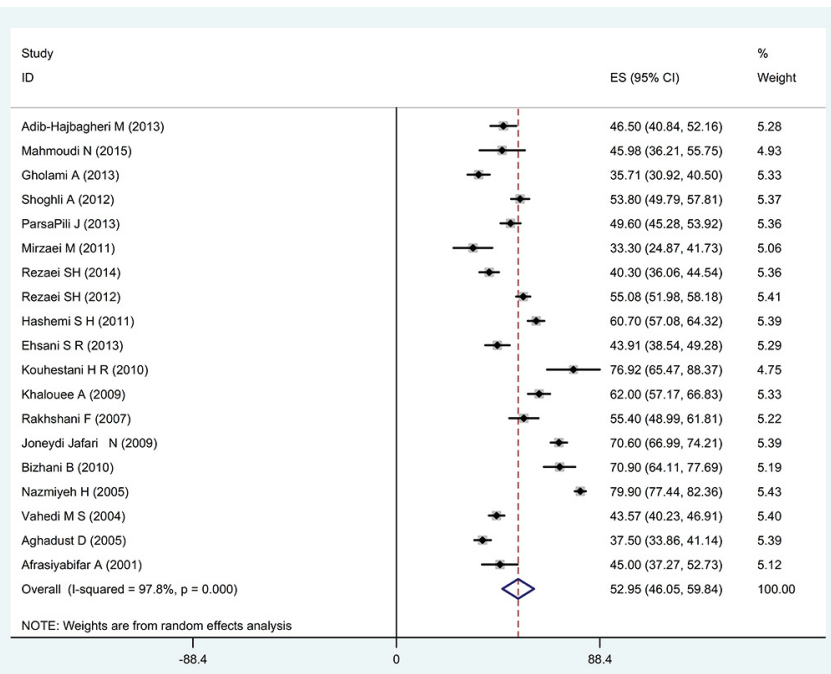

Figure 2. Needle Prevalence Based on the Reviewed Studies. Horizontal lines around the main mean show the confidence interval of $95 \%$ for each study. The dotted line in the middle indicates the estimated total prevalence, and the lozenge shows the confidence interval of the total prevalence of needle-related injuries. different countries. In Japan, a study by Yoshikawa et al on 5463 cases showed that the disposable syringe was the most common device causing injuries in $25.4 \%$ of cases. ${ }^{34}$

Using safety equipment and following standard precautions are very important to decreasing device-related injuries. ${ }^{34}$

The frequency of NSIs is a major occupational health issue around the world, especially in countries with limited safety equipment resources. ${ }^{35}$ In the study by Smith et al among Japanese nurses, the needle was the common device in $31.3 \%$ of injuries. ${ }^{36}$ The high prevalence of NSIs in the current findings compared with other studies emphasizes the role of education and the importance of recapping and practicing strict precautionary actions after using devices with needles. ${ }^{32}$

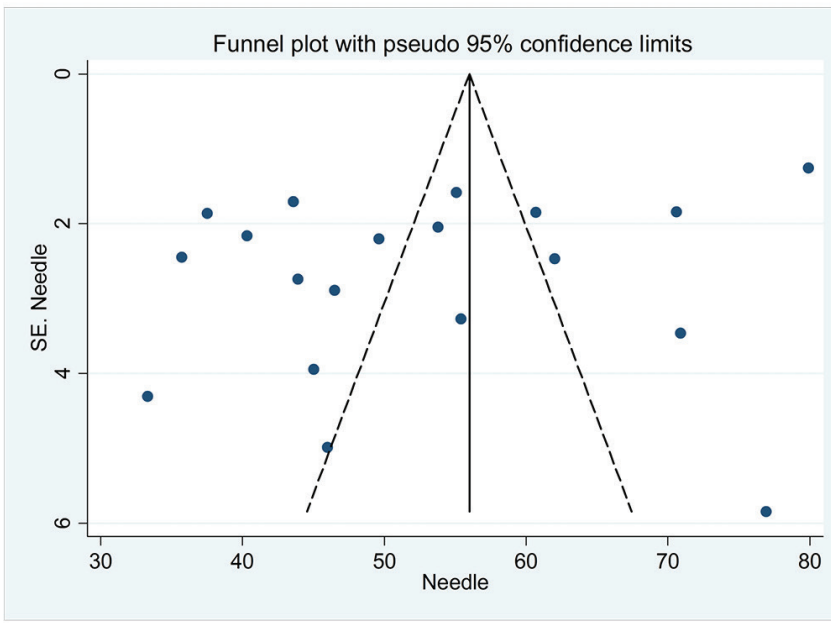

Figure 3. Funnel Plot to Assess Publication Bias for Prevalence of Needle as a Common Object in Occupational Injuries. 


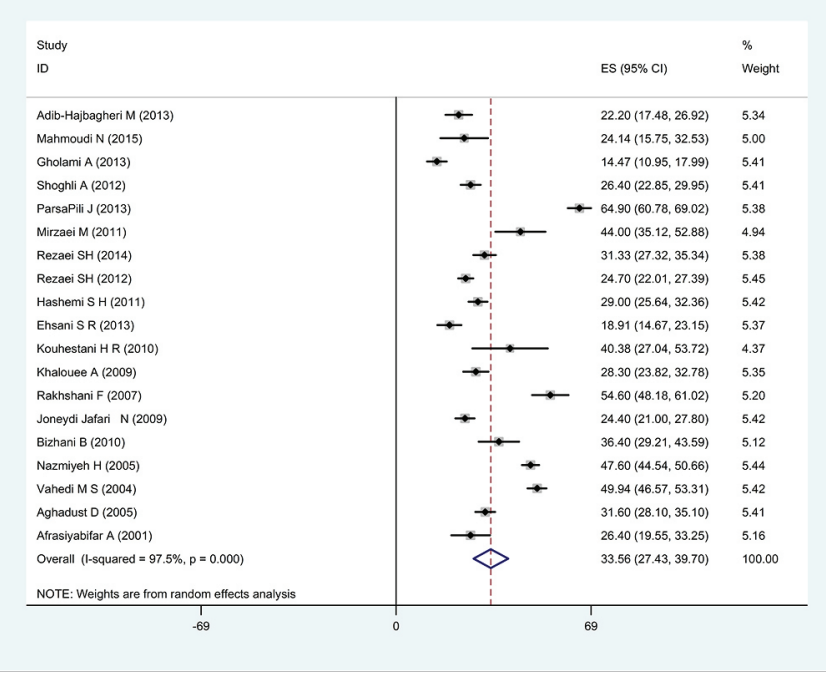

Figure 4. Prevalence of Injections Based on the Reviewed Studies. Horizontal lines around the main mean show the confidence interval of $95 \%$ for each study. The dotted line in the middle indicates the estimated total prevalence, and the lozenge shows the confidence interval of the total prevalence of injection-related injuries.

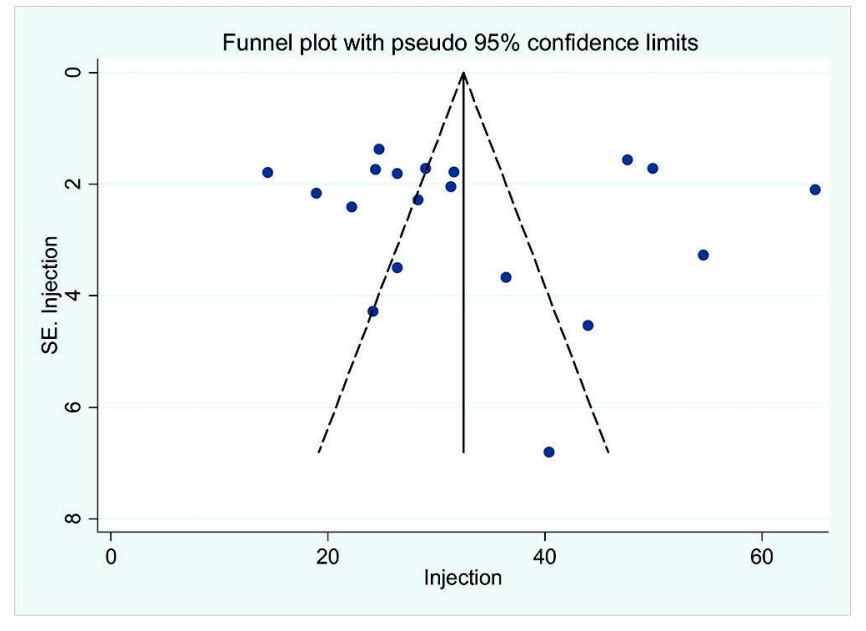

Figure 5. Funnel Plot to Assess Publication Bias for Prevalence of Injections as Common Activity in Occupational Injuries.

The results of the current study showed a wide variation in the prevalence rates of injection-related injuries among HCWs in Iran. The prevalence of injection-related occupational injuries among Iranian HCWs was estimated to be $33.56 \%$ (confidence interval 95\%-27.43-37.90) using the random effect model. This is higher than the prevalence of injectionrelated injuries reported by Martin et $a .^{33}$ In their study, they showed that injection was the most common cause of activity-related injuries among HCWs. ${ }^{33}$ In a study by Afridi et al in Pakistan, $41.9 \%$ of HCWs were injured while giving injections or drawing blood samples. ${ }^{37}$ Injection was the most common cause of activity-related injuries in the findings of the studies of Laishram et al, ${ }^{38}$ Quien et al, ${ }^{39}$ Nsubuga et $a l,{ }^{40}$ and Kebede et al. ${ }^{32}$

Caution must be taken when comparing the current findings with those of the above-mentioned studies. This article is the analysis of 19 studies, while the other mentioned papers were based on one study. Because of the high prevalence rates of device-related and activity-related injuries in Iranian HCWs, it is necessary to establish effective precautionary standards and safety measures to reduce occupational injuries among HCWs.

This meta-analysis has two limitations. First, because of the heterogeneity of the studies and the fact that this metaanalysis was restricted to studies on Iran, caution must be taken in interpreting and generalizing the findings to other health care settings around the world. Secondly, differences in participant occupation, gender, sample size, location, type of hospital (public or private), and experiences of HCWs require that the current findings be interpreted with caution.

\section{Conclusions}

This study found the overall prevalence rates of needlerelated and injection-related injuries among HCWs in Iran to be $52.95 \%$ and $33.56 \%$, respectively. The impact occupational injuries have on the quality of patient care, the safety of HCWs, and health care costs demand that effective measures be applied to prevent or decrease the frequency of occupational injuries.

\section{Authors' Contributions}

ZF was involved in the database search, extracting data, the early drafting of the manuscript and revising the manuscript; $\mathrm{AD}$ acted as advisor in all stages of the research as well as statistical analysis; MNK contributed to the conception and design of the study, extracting data and aided in writing and revising the manuscript.

\section{Conflict of Interest Disclosures}

The authors declare they have no conflicts of interest.

\section{Funding/Support}

Fasa University of Medical Sciences, Fasa, Iran supported this study.

\section{Acknowledgements}

This article was extracted from an approved research project by Fasa University of Medical Sciences, Fasa, Iran. We thank the Deputy for Research of Fasa University of Medical Sciences for the support given to this project.

\section{References}

1. Himmelreich $\mathrm{H}$, Rabenau HF, Rindermann M, et al. The management of needlestick injuries. Dtsch Arztebl Int. 2013;110(5):61-67. doi:10.3238/arztebl.2013.0061.

2. Vaz K, McGrowder D, Alexander-Lindo R, Gordon L, Brown P, Irving R. Knowledge, awareness and compliance with universal precautions among health care workers at the University Hospital of the West Indies, Jamaica. Int J Occup Environ Med. 2010;1(4):171181.

3. Jahan S. Epidemiology of needlestick injuries among health care workers in a secondary care hospital in Saudi Arabia. Ann Saudi Med. 2005;25(3):233-238. doi:10.5144/0256-4947.2005.233.

4. Chow J, Rayment G, Wong J, Jefferys A, Suranyi M. Needle-stick injury: a novel intervention to reduce the occupational health and safety risk in the haemodialysis setting. J Ren Care. 2009;35(3):120126. doi:10.1111/j.1755-6686.2009.00093.x. 
5. Talaat M, Kandeel A, El-Shoubary W, et al. Occupational exposure to needlestick injuries and hepatitis $B$ vaccination coverage among health care workers in Egypt. Am J Infect Control. 2003;31(8):469474. doi:10.1016/j.ajic.2003.03.003.

6. Atenstaedt RL, Payne S, Roberts RJ, Russell IT, Russell D, Edwards RT. Needle-stick injuries in primary care in Wales. J Public Health (Oxf). 2007;29(4):434-440.doi:10.1093/pubmed/fdm048.

7. Gershon RR, Mitchell C, Sherman MF, et al. Hepatitis B vaccination in correctional health care workers. Am J Infect Control. 2005;33(9):510-518. doi:10.1016/j.ajic.2005.04.245.

8. Adib-Hajbaghery M, Lotfi MS. Behavior of healthcare workers after injuries from sharp instruments. Trauma Mon. 2013;18(2):75-80. doi:10.5812/traumamon.12779.

9. Jagger J, Berguer R, Phillips EK, Parker G, Gomaa AE. Increase in sharps injuries in surgical settings versus nonsurgical settings after passage of national needlestick legislation. AORN J. 2011;93(3):322330. doi:10.1016/j.aorn.2011.01.001.

10. Dement JM, Epling C, Ostbye T, Pompeii LA, Hunt DL. Blood and body fluid exposure risks among health care workers: results from the Duke Health and Safety Surveillance System. Am J Ind Med. 2004;46(6):637-648. doi:10.1002/ajim.20106.

11. Rezaei S, Rabirad N, Tamizi Z, Fallahi Khoshknab M, Mohammadnejad E, Mahmoodi M. Needle sticks injuries among heath care workers in emergency medical centers in Tehran University of Medical Sciences Hospitals (2007-2010). Journal of Health Promotion Management. 2012;1(3):46-55.

12. Gourni P, Polikandrioti M, Vasilopoulos G, Mpaltzi E, Gourni M. Occupational exposure to blood and body fluids of nurses at emergency department. Health Sci J. 2012;6(1):60-68.

13. Honda M, Chompikul J, Rattanapan C, Wood G, Klungboonkrong S. Sharps injuries among nurses in a Thai regional hospital: prevalence and risk factors. Int J Occup Environ Med. 2011;2(4):215-223.

14. Motaarefi H, Mahmoudi H, Mohammadi E, Hasanpour-Dehkordi A. Factors Associated with Needlestick Injuries in Health Care Occupations: A Systematic Review. J Clin Diagn Res. 2016;10(8):le01-ie04. doi:10.7860/jcdr/2016/17973.8221.

15. Mahmoudi N, Sepandi M, Sheikh Mohammadi A, Masoumbeigi H. Epidemiological Aspects of Needle Stick Injuries among Nurses in a Military Hospital. Iran J Health Saf Environ. 2015;2(4):374-379.

16. Gholami A, Borji A, Lotfabadi P, Asghari A. Risk factors of needlestick and sharps injuries among healthcare workers. Int J Hosp Res. 2013;2(1):31-38.

17. Shoghli A, Mousavi Nasab N, Ghorchian F, Masoumi H, Momtazi S. Study of the needle sticks injury (NSI) among the Zanjan educational hospitals staff. Journal of Zanjan University of Medical Sciences. 2013;21(85):131-141.

18. Parsa-Pili J, Izadi N, Golbabaei F. Factors associated with needle stick and Sharp injuries among health care workers. Int J Occup Hyg. 2015;5(4):191-197.

19. Mirzaei M, Khozaei S, Rezaeian Langroudi R, Zahra Z. Prevalence, causes \& practice of nursing in releated to occupational exposures in Hamadan. Aflak Journal. 2011;24(25):24-31. [Persian].

20. Rezaei S, Rad NR, Tamizi Z, Khoshknab MF, Nezhad EM. An Investigation into Occupational Hazards Faced by Nurses in Paediatrics Hospitals of Tehran University of Medical Sciences, 2006-2009. Int J Community Based Nurs Midwifery. 2013;1(4):200207.

21. Hashemi SH, Torabian S, Mamani M, Moazen Dehkordi S. The prevalence of needlestick and sharps injuries among health care workers in Hamadan, Iran. Avicenna J Clin Med. 2012;18(4):41-46.

22. Ehsani SR, Mohammadnejad E, Hadizadeh MR. Epidemiology of needle sticks and sharp injuries among nurses in an Iranian teaching hospital. Arch Clin Infect Dis. 2012;8(1):27-30. doi:10.5812/ archcid.14409

23. Koohestani HR, Baghcheghi N, Rezaei K. Blood contaminated needle stick/sharp objects injuries and exposure to patients' body fluids in medical emergencies students. Iran J Crit Care Nurs.

\section{0;3(2):57-62}

24. Khalouei Z, Iranpour A, Hamzehnezhadi S, Rahmanian K. Study on epidemiology of needle stick injury among nursing personnel of Kerman University hospitals. Kerman, Iran in (2006-2007). Journal of Jahrom University of Medical Sciences. 2010;7(3):43-51. [Persian].

25. Rakhshani F, Heidari MT, Barati S. Prevalence of needlestick injuries among the healthcare professionals in Zahedan medical Sciences university. Iran J Epidemiol. 2009;4(3-4):87-91.

26. Jonaidi Jafari NA, Shasti M, Izadi M, Ranjbar R, Ghasemi M. Evaluation of frequency of exposure to medical sharp devices among nurses of a university hospital. J Mil Med. 2008;10(2):119-128.

27. Bijani B, Azimiyan J, Soleimany MA, Mohammadi N. Epidemiology and risk factors of needle stick injuries among nurses in Bou-Ali Sina teaching hospital, Qazvin. J Shahid Beheshti Nursing and Midwifery. 2012;22(78):1-8. [Persian].

28. Nazmieh H, Najaf-Yarandi A, Janmohammadi S, Hoseini F. Assesment of the injuries caused by sharp instruments in the health workers of university hospitals in Yazd. Iran Journal of Nursing. 2005;18(43):49-59.

29. Vahedi MS, Ahsan B, Ardalan M, Shahsavari S. Prevalence and Causes of needle stick injuries, in medical personnels of Kurdistan University's hospitals and dealing with such injuries due to contaminated sharp tools in 1383. Scientific Journal of Kurdistan University of Medical Sciences. 2006;11(2):43-50. [Persian].

30. Aghadoost $D$, Hajijafari $M$, Tabatabaei B, Ziloochi MH, Dalirian A. Occupational exposure to blood in the stuff of educational-medical centers of Kashan University of Medical Sciences in 2005. Feyz. 2007;10(4):59-64. [Persian].

31. Afrasiabifar A, Salari M, Zarifi A, Mohebi Z. Skin penetrating injuries due to the insertion of sharp medical instruments contaminated with patients' blood or body secretion among the healthcare stuffs of Yasuj hospitals and the measures taken after injury, 2001. Journal of Yasuj University of Medical Sciences. 2003;7(28):17-23. [Persian].

32. Kebede G, Molla M, Sharma HR. Needle stick and sharps injuries among health care workers in Gondar city, Ethiopia. Saf Sci. 2012;50(4):1093-1097. doi:10.1016/j.ssci.2011.11.017.

33. Martins A, Coelho AC, Vieira M, Matos M, Pinto ML. Age and years in practice as factors associated with needlestick and sharps injuries among health care workers in a Portuguese hospital. Accid Anal Prev. 2012;47:11-15. doi:10.1016/j.aap.2012.01.011.

34. Yoshikawa T, Wada K, Lee JJ, et al. Incidence rate of needlestick and sharps injuries in 67 Japanese hospitals: a national surveillance study. PLoS One. 2013;8(10):e77524. doi:10.1371/journal. pone.0077524.

35. Rezaei S, Hajizadeh M, Zandian H, Fathi A, Nouri B. Period prevalence and reporting rate of needlestick injuries to nurses in Iran: a systematic review and meta-analysis. Res Nurs Health. 2017;40(4):311-322. doi:10.1002/nur.21801.

36. Smith DR, Mihashi $M$, Adachi $Y$, Nakashima $Y$, Ishitake $T$. Epidemiology of needlestick and sharps injuries among nurses in a Japanese teaching hospital. J Hosp Infect. 2006;64(1):44-49. doi:10.1016/j.jhin.2006.03.021.

37. Afridi AA, Kumar A, Sayani R. Needle stick injuries--risk and preventive factors: a study among health care workers in tertiary care hospitals in Pakistan. Glob J Health Sci. 2013;5(4):85-92. doi:10.5539/gjhs.v5n4p85.

38. Laishram J, Keisam A, Phesao E, Tarao MS, Laloo V, Devi HS Prevalence of needle stick injuries among nurses in a tertiary care hospital and their immediate response. Int J Med Public Health. 2013;3(4):257-260. doi:10.4103/2230-8598.123446.

39. Quinn MM, Markkanen PK, Galligan CJ, et al. Sharps injuries and other blood and body fluid exposures among home health care nurses and aides. Am J Public Health. 2009;99 Suppl 3:S710-717. doi:10.2105/ajph.2008.150169.

40. Nsubuga FM, Jaakkola MS. Needle stick injuries among nurses in sub-Saharan Africa. Trop Med Int Health. 2005;10(8):773-781. doi:10.1111/j.1365-3156.2005.01453.x. 